\title{
DANOS E NÍVEL DE DANO DO PERCEVEJO BARRIGA-VERDE Dichelops melacanthus (HEMIPTERA: PENTATOMIDAE) NA CULTURA DO TRIGO, Triticum aestivum L.
}

\author{
Marcela Marcelino Duarte' e Crébio José Ávila²
}

${ }^{1}$ Universidade Federal da Grande Dourados (UFGD), Dourados, MS, Brasil. Email: wmarceladuarte@gmail.com

2 Embrapa Agropecuária Oeste, Caixa Postal 661, CEP 79804-970 Dourados, MS, Brasil.

\section{RESUMO}

O objetivo deste trabalho foi avaliar o comportamento produtivo do trigo na presença do percevejo Dichelops melacanthus em diferentes estádios de desenvolvimento das plantas, bem como estimar o nível de dano (ND) dessa praga para essa cultura. Os experimentos foram conduzidos em casa de vegetação e na área experimental da Embrapa Agropecuária Oeste, Dourados, MS. O peso seco da parte aérea, o número de espigas, o peso das espigas e o rendimento de grãos do trigo foram influenciados pelos diferentes níveis populacionais do percevejo barriga-verde em pelo menos, duas das épocas de infestação. A intensidade de danos do percevejo barriga-verde na cultura do trigo foi influenciada pelo estádio de desenvolvimento da planta. O número de espigas e o peso de cem grãos não diferiram estatisticamente entre as diferentes densidades populacionais do percevejo. $\mathrm{O}$ nível de dano (ND) encontrado para a cultura do trigo ficou em torno de um percevejo $/ \mathrm{m}^{2}$.

Palavras-chave: Trigo, rendimento de grãos, densidade populacional, estádio da planta.

\section{DAMAGE AND DAMAGE LEVEL OF THE STINK BUG Dichelops melacanthus (HEMIP'TERA: PENTATOMIDAE) ON WHEAT (Triticum aestivum L.) CROPS}

\begin{abstract}
This work evaluates wheat yield in the presence of the stink bug D. melacanthus using different infestation periods of the plants and estimates the damage level of this pest for this crop. The experiment was set in a greenhouse and in the experimental area at Embrapa Agropecuária Oeste in Dourados, State of Mato Grosso do Sul, Brazil. Dry matter content of the upper plant part, number and weight of ears and wheat grain yields were influenced by the different stink bug population levels in at least two of the infestation periods. The wheat ear number and the weight of 100 seeds were not significantly different concerning the different infestation levels of the stink bug. The damage level was $1 \mathrm{bug} / \mathrm{square}$ meter of the wheat crop.
\end{abstract}

Key words: Wheat, grain yield, population density, plant stage 


\section{INTRODUÇÃO}

Mudanças no cenário agrícola nas Regiões Centro-Oeste e Sul do Brasil, como a expansão do sistema de plantio direto e a realização de cultivos de inverno, colaboraram para o crescimento populacional de espécies de percevejos consideradas previamente como pragas secundárias (Panizzi 1997). Áreas cultivadas no sistema plantio direto fornecem condições ideais para a sobrevivência de insetos polífagos, como por exemplo, o percevejo barriga-verde Dichelops melacanthus (Dallas, 1851) (Hemiptera: Pentatomidae), cuja população pode aumentar em níveis capazes de causar danos significativos em diversas culturas (Ávila \& Panizzi 1995). O percevejo barrigaverde é considerado praga primária na cultura do trigo e seu ataque tem sido observado desde a implantação da cultura até o espigamento (Chocorosqui \& Panizzi 2004). Estudos de monitoramento têm evidenciado um aumento significativo nas populações do percevejo barriga-verde na Região Centro-Oeste, juntamente com a redução do número de plantas e do rendimento de grãos em diferentes culturas (Link 2006). Todavia, a relação dos danos com a presença desse inseto e o seu nível de dano na maioria das culturas suscetíveis, ainda não foi devidamente avaliada. Isso tem condicionado os agricultores a realizarem aplicações de agrotóxicos em suas lavouras, sem a noção da real população que causa dano econômico (Link 2006). Essas informações, quando disponíveis, fornecem subsídios para desenvolver e adaptar tecnologias que auxiliarão o manejo integrado desse percevejo.

Assim este trabalho objetivou avaliar o desenvolvimento das plantas de trigo quando infestadas pelo percevejo barriga-verde $D$. melacanthus em diferentes estádios de desenvolvimento da planta, bem como avaliar o efeito de diferentes níveis populacionais deste percevejo no desenvolvimento das plantas de trigo, visando estimar o nível de dano dessa praga para a cultura.

\section{MATERIAL E MÉTODOS}

Os experimentos foram conduzidos em casa de vegetação e na área experimental da Embrapa Agropecuária Oeste, situada no Município de Dourados, Mato Grosso do Sul.

Danos de D. melacanthus em trigo: o experimento foi instalado em maio de 2006 utilizando-se a cultivar BR 18, que foi semeada em solo contido em vasos de seis litros, conduzindo uma população final de 14 plantas/vaso. Foram avaliadas cinco densidades populacionais da praga $(0,2,4,6$ e 8 percevejos adultos/vaso) em quatro épocas de infestação: logo após a emergência e aos 7 (plântula), 14 (três folhas) e 21 (início do perfilhamento) dias após a emergência das plantas (DAE). Os percevejos utilizados no experimento estavam na fase adulta e foram coletados em cultivos de milho e trigo da região de Dourados, MS. Sobre as plantas de cada vaso foi colocada uma armação de ferro revestida com filó para contenção dos insetos durante o período de infestação que foi de 15 dias para cada estágio de desenvolvimento da planta. As plantas foram vistoriadas diariamente para reposição de eventuais percevejos mortos. $\mathrm{O}$ experimento foi realizado no delineamento inteiramente casualizado com cinco repetições (vasos). As plantas de trigo foram realizadas até a colheita para determinação do peso seco da parte aérea, número de espigas por vaso, peso das espigas, peso de cem grãos e rendimento de grãos. Os dados obtidos nos diferentes níveis populacionais do percevejo e épocas de desenvolvimento da planta foram submetidos à análise de variância e as médias dos tratamentos comparadas pelo teste de Tukey a $5 \%$ de significância.

Nível de dano de $D$. melacanthus para o trigo: o experimento foi conduzido no campo, sendo a semeadura do trigo realizada 
em maio de 2007, seguindo as recomendações técnicas para a cultura (Reunião... 2007). A unidade experimental consistiu de uma gaiola de madeira que abrangia 160 plantas de trigo distribuídas em três filleiras de $1,12 \mathrm{~m}$ de comprimento espaçadas de $0,20 \mathrm{~m}\left(0,67 \mathrm{~m}^{2}\right)$. Quando as plantas apresentavam três folhas (fase de plântula), as gaiolas foram infestadas com diferentes níveis populacionais de adultos do percevejo $(0,2,4,6$ e 8 percevejos/gaiola), durante o período de 15 dias. Os percevejos utilizados nesse experimento foram coletados a campo em cultivos de trigo da região de Dourados, MS. As gaiolas de madeira do experimento foram revestidas na parte superior com tecido filó para contenção dos insetos, as quais foram vistoriadas diariamente para reposição de eventuais insetos mortos. $\mathrm{O}$ experimento foi conduzido no delineamento em blocos casualizados com cinco repetições (gaiolas). Após o período de infestação, os percevejos e as gaiolas foram retirados das unidades experimentais sendo as plantas pulverizadas com o inseticida clorpirifós $(480 \mathrm{~g}$ $\mathrm{ha}^{-1}$ ), para eliminar o efeito de outras pragas, que eventualmente poderiam estar presentes. $\mathrm{O}$ ensaio foi conduzido até a colheita para determinação do número de espigas e peso de cem grãos, sendo os valores obtidos nas diferentes unidades experimentais submetidos à análise de variância e as médias dos tratamentos comparadas pelo teste de Tukey a $5 \%$ de significância. Para determinação do nível de dano da praga na cultura, os dados foram submetidos à análise de regressão tendo como variável dependente os valores de rendimento de grãos e variável independente as densidades populacionais do percevejo. Para o cálculo do nível de dano econômico considerou-se o custo de controle do percevejo para a cultura do trigo equivalente a $\mathrm{R} \$ 18,60$ (dezoito reais e sessenta centavos) correspondendo a uma pulverização da mistura imidacloprido + betaciflutrina $(75,0$ $+9,4 \mathrm{~g} \mathrm{ha}^{-1}$ ) na cultura.

\section{RESULTADOS E DISCUSSÃO}

Danos de $D$. melacanthus em trigo: o peso seco da parte aérea do trigo por ocasião da colheita foi significativamente influenciado pelas diferentes densidades populacionais do percevejo estudadas, em todas as quatro épocas de infestação analisadas (Tabela 1). Na primeira época (logo após a emergência), apenas a densidade populacional de dois percevejos/vaso reduziu significativamente o peso seco da parte aérea do trigo quando comparado à testemunha, enquanto que aos sete dias após a emergência (7 DAE) essa redução foi observada somente com o nível de quatro percevejos/vaso. Este comportamento inesperado pode ser decorrente do fato de terem sido utilizados percevejos provenientes do campo, com idades e condições fisiológicas variáveis. Já aos $14 \mathrm{DAE}$, as densidades populacionais de quatro, seis e oito percevejos/vaso proporcionaram redução significativa no peso seco da parte aérea do trigo, quando comparada à testemunha, sem diferir estatisticamente entre si. Aos 21 DAE somente os níveis de seis e oito percevejos/vaso causaram redução significativa no peso seco da parte aérea do trigo (Tabela 1), sendo este estádio o início do perfillhamento. 
Tabela 1. Peso seco médio da parte aérea do trigo por vaso $\left(\overline{\mathrm{X}} \pm \mathrm{EP}^{1}\right)$, quando infestado com adultos de Dichelops melacanthus, logo após emergência e aos 7, 14 e 21 dias após a emergência (DAE), em casa de vegetação. Dourados, MS. 2006.

\begin{tabular}{ccccc}
\hline \multirow{2}{*}{ Percevejos/vaso } & \multicolumn{4}{c}{ Época de infestação } \\
\cline { 2 - 5 } & Logo após emergência & $7 \mathrm{DAE}$ & $14 \mathrm{DAE}$ & $21 \mathrm{DAE}$ \\
\hline 0 & $12,5 \pm 0,90 \mathrm{a}$ & $12,5 \pm 0,90 \mathrm{a}$ & $12,5 \pm 0,90 \mathrm{a}$ & $12,5 \pm 0,90 \mathrm{a}$ \\
2 & $9,30 \pm 0,75 \mathrm{~b}$ & $10,0 \pm 0,77 \mathrm{ab}$ & $10,3 \pm 0,47 \mathrm{ab}$ & $10,3 \pm 0,65 \mathrm{ab}$ \\
4 & $10,0 \pm 0,63 \mathrm{ab}$ & $9,3 \pm 0,32 \mathrm{~b}$ & $8,5 \pm 0,60 \mathrm{~b}$ & $9,6 \pm 0,63 \mathrm{abc}$ \\
6 & $10,0 \pm 0,11 \mathrm{ab}$ & $9,8 \pm 0,54 \mathrm{ab}$ & $8,6 \pm 0,65 \mathrm{~b}$ & $6,7 \pm 0,93 \mathrm{c}$ \\
8 & $10,1 \pm 0,50 \mathrm{ab}$ & $9,9 \pm 0,48 \mathrm{ab}$ & $8.8 \pm 0,99 \mathrm{~b}$ & $8,2 \pm 0,86 \mathrm{bc}$ \\
\hline
\end{tabular}

Médias seguidas da mesma letra, na coluna, não diferem estatisticamente pelo teste de Tukey $(p \leq 0,05)$.

${ }^{1}$ Erro padrão da média.

Com relação ao número de espigas por vaso constatou-se que essa variável foi significativamente influenciada pelas diferentes densidades populacionais do percevejo, que foram colocadas nos vasos nas três primeiras épocas de infestação, ou seja, logo após emergência e aos 7 e 14 DAE (Tabela 2). Logo após emergência, as densidades populacionais de dois, seis e oito percevejos/vaso reduziram significativamente o número de espigas de trigo quando comparado à testemunha, enquanto que aos 7 DAE essa redução foi verificada a partir de quatro percevejos/vaso. Aos $14 \mathrm{DAE}$, as densidades populacionais de seis e oito percevejos/vaso continuaram proporcionando redução significativa do número de espigas quando comparada à testemunha, enquanto que aos 21 DAE essa variável não foi influenciada pelas diferentes densidades populacionais do percevejo. Isso provavelmente ocorreu porque aos 21 DAE as espigas na planta de trigo já estariam definidas, já que segundo Teruel \& Smiderle (1999), o número de espigas de trigo é determinado no início do desenvolvimento da planta. Os resultados obtidos indicam que até os $14 \mathrm{DAE}$ do trigo, a presença do percevejo barriga-verde pode reduzir o número de espigas na planta, mas que aos $21 \mathrm{DAE}$ as plantas não são mais suscetíveis ao ataque do percevejo com relação a essa variável. Esse resultado corrobora com o observado por Chocorosqui \& Panizzi (2004), onde infestações realizadas com quatro percevejos/vaso não influenciaram o número de espigas nas plantas de trigo na fase de perfilhamento.

Tabela 2. Número médio de espigas do trigo por vaso $\left(\overline{\mathrm{X}} \pm \mathrm{EP}^{1}\right)$, quando as plantas foram infestadas com adultos de Dichelops melacanthus, logo após emergência e aos 7, 14 e 21 dias após a emergência (DAE), em casa de vegetação. Dourados, MS. 2006.

\begin{tabular}{ccccc}
\hline \multirow{2}{*}{ Percevejos/vaso } & \multicolumn{4}{c}{ Época de infestação } \\
\cline { 2 - 5 } & Logo após emergência & 7 DAE & 14 DAE & 21 DAE \\
\hline 0 & $14,6 \pm 0,19 \mathrm{a}$ & $14,6 \pm 0,19 \mathrm{a}$ & $14,6 \pm 0,19 \mathrm{a}$ & $14,6 \pm 0,19 \mathrm{~ns}^{2}$ \\
2 & $9,8 \pm 0,58 \mathrm{~b}$ & $11,4 \pm 0,87 \mathrm{ab}$ & $12,4 \pm 0,68 \mathrm{ab}$ & $14,8 \pm 0,20$ \\
4 & $11,4 \pm 1,12 \mathrm{ab}$ & $10,6 \pm 0,40 \mathrm{~b}$ & $11,0 \pm 0,71 \mathrm{ab}$ & $12,6 \pm 0,93$ \\
6 & $10,6 \pm 0,60 \mathrm{~b}$ & $9,4 \pm 0,93 \mathrm{~b}$ & $9,4 \pm 0,93 \mathrm{~b}$ & $12,0 \pm 1,10$ \\
8 & $10,6 \pm 0,75 \mathrm{~b}$ & $10,2 \pm 1,11 \mathrm{~b}$ & $8,8 \pm 1,28 \mathrm{~b}$ & $12,6 \pm 0,93$ \\
\hline
\end{tabular}

Médias seguidas da mesma letra, na coluna, não diferem estatisticamente pelo teste de Tukey $(p \leq 0,05)$.

${ }^{1}$ Erro padrão da média.

${ }^{2}$ ns=Não significativo na análise de variância pelo teste $\mathrm{F}(\mathrm{p}>0,05)$. 
Foi também constatada redução significativa no peso das espigas de trigo quando as plantas foram infestadas com o percevejo aos 7, 14 e $21 \mathrm{DAE}$ (Tabela 3). Na primeira época de infestação (logo após a emergência) essa variável não foi influenciada pelas diferentes densidades populacionais do percevejo. Isso, provavelmente, ocorreu porque nesta fase de desenvolvimento do trigo as espigas não haviam ainda sido formadas na planta, enquanto nas plantas mais desenvolvidas, especialmente aos 14 e $21 \mathrm{DAE}$, as espigas já estavam formadas ou em processo de formação e, desta forma, foram afetadas pela presença do percevejo. Aos $7 \mathrm{DAE}$, apenas o nível de seis percevejos/vaso ocasionou redução significativa no peso das espigas. Aos 14 e 21 DAE, a partir do nível de quatro percevejos/vaso verificou-se redução significativa no peso das espigas de trigo, em relação às plantas sem infestação. Embora os diferentes níveis populacionais não tivessem influenciado o número de espigas do trigo aos 21 DAE (Tabela 2), o enchimento de grãos foi afetado neste estádio de desenvolvimento, possivelmente porque a planta debilitada pelo ataque do percevejo afetou negativamente a produção de fotoassimilados para a formação do grão. Com base nos resultados obtidos, pode-se inferir que quando o ataque do percevejo ocorre no início do desenvolvimento do trigo, as injúrias do inseto não interferem no peso das espigas produzidas. Segundo Manfredi-Coimbra et al. (2005), a alimentação do percevejo barriga-verde durante a fase de perfilhamento do trigo, afeta de forma negativa o enchimento de grãos.

Tabela 3. Peso médio das espigas do trigo por vaso $\left(\overline{\mathrm{X}} \pm \mathrm{EP}^{1}\right)$, quando as plantas foram infestadas por adultos de Dichelops melacanthus, logo após emergência e aos 7, 14 e 21 dias após a emergência (DAE), em casa de vegetação. Dourados, MS. 2006.

\begin{tabular}{ccccc}
\hline \multirow{2}{*}{ Percevejos/vaso } & \multicolumn{4}{c}{ Época de infestação } \\
\cline { 2 - 5 } & Logo após emergência & $7 \mathrm{DAE}$ & \multicolumn{1}{c}{$14 \mathrm{DAE}$} & \multicolumn{1}{c}{$21 \mathrm{DAE}$} \\
\hline 0 & $6,3 \pm 0,40 \mathrm{~ns}^{2}$ & $6,3 \pm 0,40 \mathrm{a}$ & $6,3 \pm 0,40 \mathrm{a}$ & $6,3 \pm 0,40 \mathrm{a}$ \\
2 & $5,7 \pm 0,18$ & $6,0 \pm 0,36 \mathrm{ab}$ & $5,5 \pm 0,11 \mathrm{ab}$ & $5,4 \pm 0,49 \mathrm{ab}$ \\
4 & $5,5 \pm 0,38$ & $5,3 \pm 0,31 \mathrm{ab}$ & $4,6 \pm 0,25 \mathrm{~b}$ & $4,4 \pm 0,45 \mathrm{bc}$ \\
6 & $5,7 \pm 0,21$ & $4,9 \pm 0,34 \mathrm{~b}$ & $4,2 \pm 0,27 \mathrm{~b}$ & $3,5 \pm 0,35 \mathrm{c}$ \\
8 & $5,5 \pm 0,22$ & $6,0 \pm 0,20 \mathrm{ab}$ & $4,3 \pm 0,48 \mathrm{~b}$ & $4,1 \pm 0,45 \mathrm{bc}$ \\
\hline
\end{tabular}

Médias seguidas da mesma letra, na coluna, não diferem estatisticamente pelo teste de Tukey $(p \leq 0,05)$.

${ }^{1}$ Erro padrão da média.

${ }^{2} \mathrm{~ns}=$ Não significativo na análise de variância pelo teste $\mathrm{F}(\mathrm{p}>0,05)$.

$O$ peso de cem grãos não foi significativamente influenciado pelas diferentes densidades populacionais do percevejo, quando a infestação foi realizada logo após a emergência da planta e aos 7 DAE (Tabela 4). No entanto, aos 14 e 21 DAE esta variável foi significativamente reduzida na presença do percevejo. Quando as infestações foram realizadas aos 14 DAE, observaram-se reduções significativas no peso de cem grãos do trigo a partir de quatro percevejos/vaso em relação às plantas sem infestação. Já aos 21 DAE todos os níveis populacionais testados reduziram significativamente o peso de cem grãos de trigo, quando comparados à testemunha, sem diferirem entre si. Os resultados evidenciam que o ataque do percevejo barriga-verde no trigo nos períodos de 14 e 21 DAE influencia o enchimento de grãos da planta. Outros trabalhos também evidenciaram que a alimentação do percevejo barriga-verde durante a fase de perfilhamento do trigo tem efeito negativo direto sobre enchimento de grãos. Chocorosqui \& Panizzi (2004) verificaram que há um 
percentual de $3,2 \%$ de espigas chochas, quando desenvolvimento. o ataque do percevejo ocorre neste estádio de

Tabela 4. Peso médio de grãos do trigo por vaso $\left(\bar{X} \pm \mathrm{EP}^{1}\right)$, quando as plantas foram infestadas por adultos de Dichelops melacanthus, logo após emergência e aos 7, 14 e 21 dias após a emergência (DAE), em casa de vegetação. Dourados, MS. 2006.

\begin{tabular}{ccccc}
\hline \multirow{2}{*}{ Percevejos/vaso } & \multicolumn{4}{c}{ Época de infestação } \\
\cline { 2 - 5 } & Logo após emergência & 7 DAE & 14 DAE & 21 DAE \\
\hline 0 & $4,2 \pm 0,25 \mathrm{~ns}^{2}$ & $4,2 \pm 0,25 \mathrm{~ns}$ & $4,2 \pm 0,25 \mathrm{a}$ & $4,2 \pm 0,25 \mathrm{a}$ \\
2 & $4,0 \pm 0,08$ & $4,2 \pm 0,45$ & $3,7 \pm 0,02 \mathrm{ab}$ & $3,1 \pm 0,05 \mathrm{~b}$ \\
4 & $4,1 \pm 0,03$ & $3,9 \pm 0,04$ & $3,5 \pm 0,03 \mathrm{~b}$ & $3,0 \pm 0,04 \mathrm{~b}$ \\
6 & $3,9 \pm 0,05$ & $3,7 \pm 0,47$ & $3,4 \pm 0,09 \mathrm{~b}$ & $2,8 \pm 0,04 \mathrm{~b}$ \\
8 & $4,2 \pm 0,07$ & $3,9 \pm 0,85$ & $3,4 \pm 0,09 \mathrm{~b}$ & $3,2 \pm 0,24 \mathrm{~b}$ \\
\hline
\end{tabular}

Médias seguidas da mesma letra, na coluna, não diferem estatisticamente pelo teste de Tukey $(p \leq 0,05)$.

${ }^{1}$ Erro padrão da média.

${ }^{2}$ ns=Não significativo na análise de variância pelo teste $F(p>0,05)$.

O rendimento de grãos do trigo não foi significativamente influenciado pelas densidades populacionais do percevejo quando as infestações foram realizadas logo após a emergência da planta e aos $7 \mathrm{DAE}$, porém aos 14 e 21 DAE a produtividade do trigo foi significativamente reduzida com as maiores densidades populacionais estudadas (Tabela 5). Quando as infestações foram realizadas aos 14 DAE, observaram-se reduções significativas no rendimento de grãos de trigo a partir de quatro percevejos/vaso, sendo constatada redução de até $29 \%$ no rendimento de grãos, quando comparado às plantas sem infestação. Já aos 21 DAE, apenas as duas maiores densidades populacionais (seis e oito percevejos/vaso) causaram reduções significativas de até $50,8 \%$ no rendimento de grãos do trigo quando comparados a testemunha, sem que diferissem estatisticamente entre si.

Tabela 5. Rendimento médio de grãos do trigo por vaso $\left(\overline{\mathrm{X}} \pm \mathrm{EP}^{\mathrm{j}}\right)$ quando as plantas foram infestadas ou não por adultos de Dichelops melacanthus, logo após a emergência e aos 7, 14 e 21 dias após a emergência (DAE), em casa de vegetação. Dourados, MS. 2006.

\begin{tabular}{ccccc}
\hline \multirow{2}{*}{ Percevejos/vaso } & \multicolumn{4}{c}{ Época de infestação } \\
\cline { 2 - 5 } & Logo após emergência & 7 DAE & $14 \mathrm{DAE}$ & $21 \mathrm{DAE}$ \\
\hline 0 & $4,0 \pm 0,27 \mathrm{~ns}^{2}$ & $4,0 \pm 0,27 \mathrm{~ns}$ & $4,0 \pm 0,27 \mathrm{a}$ & $4,0 \pm 0,27 \mathrm{a}$ \\
2 & $3,8 \pm 0,27$ & $4,0 \pm 0,31$ & $3,6 \pm 0,13 \mathrm{ab}$ & $3,3 \pm 0,42 \mathrm{ab}$ \\
4 & $3,5 \pm 0,29$ & $3,7 \pm 0,07$ & $2,9 \pm 0,23 \mathrm{~b}$ & $2,8 \pm 0,34 \mathrm{ab}$ \\
6 & $3,7 \pm 0,22$ & $3,2 \pm 0,21$ & $2,9 \pm 0,17 \mathrm{~b}$ & $2.0 \pm 0,18 \mathrm{~b}$ \\
8 & $3,3 \pm 0,30$ & $4,0 \pm 0,11$ & $2,9 \pm 0,30 \mathrm{~b}$ & $2,6 \pm 0,34 \mathrm{~b}$ \\
\hline
\end{tabular}

Médias seguidas da mesma letra, na coluna, não diferem estatisticamente pelo teste de Tukey $(p \leq 0,05)$.

${ }^{1}$ Erro padrão da média.

${ }^{2} \mathrm{~ns}=$ Não-significativo na análise de variância pelo teste $\mathrm{F}(\mathrm{p}>0,05)$.

Com base nos resultados obtidos podese inferir que as plantas de trigo não apresentam suscetibilidade ao ataque de D. melacanthus com relação ao rendimento de grãos, quando o ataque ocorre no início do desenvolvimento das plantas, porém esta suscetibilidade é verificada aos 14 e 21 DAE. Segundo Bianco (2005) a ocorrência do percevejo barriga-verde tem sido observada desde a implantação da cultura do trigo até o espigamento, sendo a fase mais suscetível ao ataque do percevejo, a do emborrachamento ao espigamento, 
corroborando com o verificado nesta pesquisa. No entanto, Chocorosqui \& Panizzi (2004) relataram que todas as fases de desenvolvimento do trigo são suscetíveis ao ataque de D. melacanthus.

Quando se analisou o rendimento de grãos de trigo considerando-se o efeito médio das diferentes densidades populacionais do percevejo, no intervalo de dois a oito percevejos/vaso nas diferentes épocas de infestação da planta, constatou-se significativamente menor rendimento aos 21 DAE, quando comparado às infestações realizadas logo após a emergência (0 DAE) ou aos 7 DAE (Figura 1). Este resultado concorda com o observado por Chocorosqui \& Panizzi (2004) em que a menor produção de grãos/vaso, devido à alimentação do percevejo, ocorreu também na fase de perfilhamento (21 DAE). Tais resultados reforçam a evidência de que as plantas de trigo apresentam diferenças em suscetibilidade ao ataque do percevejo $D$. melacanthus em função da sua época de desenvolvimento e que os estádios próximos ao perfilhamento e emborrachamento são suscetíveis ao ataque dessa praga.

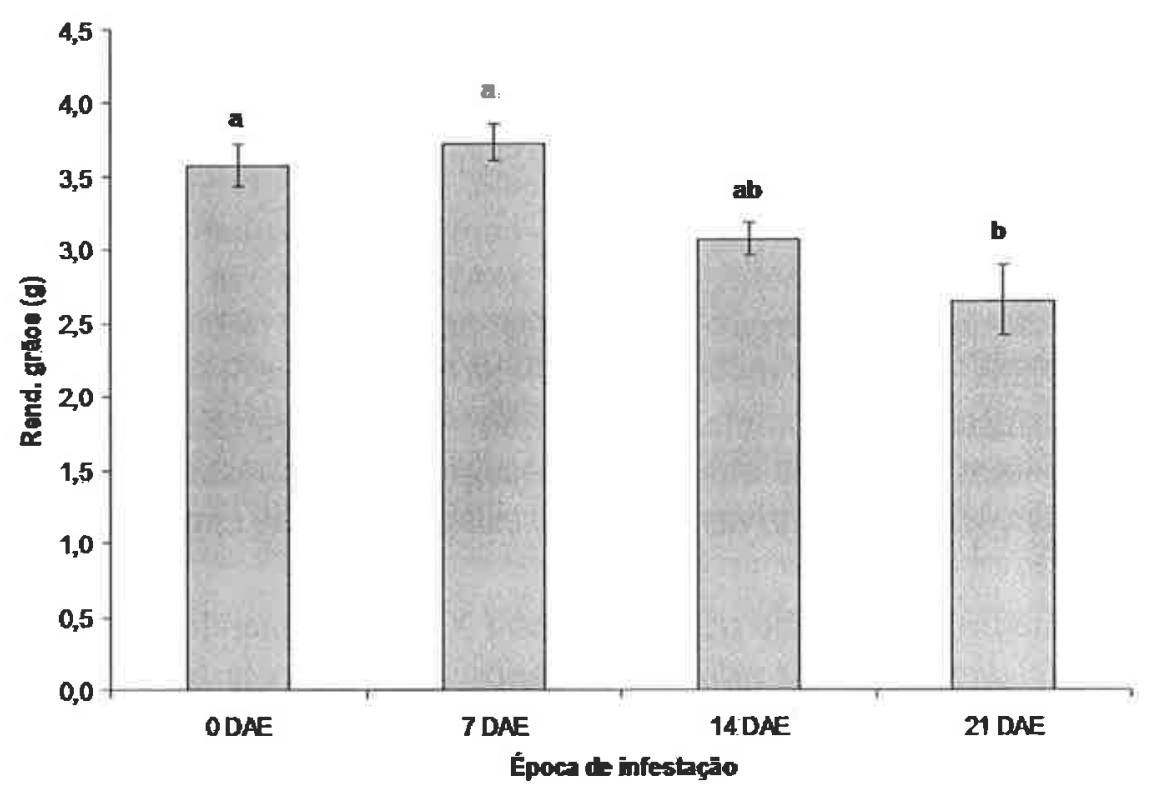

Figura 1. Rendimento médio de grãos ( $\mathrm{g}$ ) do trigo quando infestado por percevejos adultos de Dichelops melacanthus (média de dois a oito percevejos/vaso) nas diferentes épocas de infestação, em casa de vegetação. Dourados-MS, 2006.

Nível de dano de $D$. melacanthus no trigo: na análise de rendimento de grãos foi constatada relação negativa e significativa entre os níveis de infestação do percevejo e os valores de rendimento de grãos para a cultura de trigo (Figura 2). Verificou-se, dessa forma, que o aumento da densidade populacional do percevejo barriga-verde afetou negativamente $o$ rendimento de grãos dessa cultura, relação esta que foi significativamente ajustada no modelo linear de regressão $\left(\mathrm{R}^{2}=0,92\right)$, com um nível de significância inferior a $1 \%$ (Figura 2). Segundo Chocorosqui \& Panizzi (2004), o ataque de $D$. melacanthus em plântulas de trigo pode ocasionar redução na produção de grãos de $30 \%$, dependendo da intensidade de infestação e do estádio de desenvolvimento da planta. 
de controle deste percevejo, porém esses valores de nível de dano podem variar de ano para ano, dependendo do nível produtividade da cultura, suscetibilidade da cultivar, do tipo de solo, do estádio de desenvolvimento da planta em que ocorre o ataque da praga e do custo empregado no controle dessa praga.

\section{CONCLUSÃO}

Os resultados deste estudo demonstraram que a intensidade de danos do percevejo barriga-verde na cultura do trigo é influenciada pelo estádio de desenvolvimento da planta e que todas as variáveis avaliadas sofreram reduções significativas em pelo menos duas das épocas de infestação. $\mathrm{O}$ nível de dano do percevejo barriga-verde para a cultura do trigo está em torno de um percevejo $/ \mathrm{m}^{2}$, quando o ataque ocorre no início do desenvolvimento da cultura.

\section{AGRADECIMENTOS}

Os autores manifestam seus agradecimentos às seguintes Instituições: Universidade Federal da Grande Dourados, Embrapa Agropecuária Oeste e à FUNDECT.

\section{REFERÊNCIAS BIBLIOGRÁFICAS}

ÁVILA, C.J.; PANIZZI, A.R. 1995. Occurrence and damage by Dichelops (Neodichelops) melacanthus (Dallas) (Heteroptera: Pentatomidae) on corn. Anais da Sociedade Entomológica do Brasil 24: 193-194.

BIANCO, R. 2005. O percevejo barriga-verde no milho e no trigo em plantio direto. Revista Plantio Direto, 89: 46-49, 51.
CHOCOROSQUI, V.R.; PANIZZI, A.R. 2004. Impact of cultivation systems on Dichelops melacanthus (Dallas) (Heteroptera: Pentatomidae) population and damage and its chemical control on wheat. Neotropical Entomology 33: 487-492.

CROCOMO, W. B. (org.) 1990. Manejo integrado de pragas. São Paulo, EDUNESP, v.1, 358p.

LINK, D. 2006. Praga na emergência. Cultivar: grandes culturas $88: 32-33$.

MANFREDI-COIMBRA, S.; SILVA, J.J.; CHOCOROSQUI, V.R.; PANIZZI, A.R. 2005. Danos do percevejo barriga-verde Dichelops melacanthus (Dallas) (Heteroptera: Pentatomidae) em trigo. Ciência Rural 35: 1243-1247.

PANIZZI, A.R. 1997. Entomofauna changes with soybean expansion in Brazil, p.166169. In World Soybean Research Conference, 5., 1994, Chiang Mai. Soybean feeds the world: Proceedings. Bangkok, Kasetsart University Press.

REUNIÃO DA COMISSÃO SULBRASILEIRA DE PESQUISA DE TRIGO E TRITICALE, 38.; REUNIÃO DA COMISSÃO CENTRO-SUL BRASILEIRA DE PESQUISA DE TRIGO E TRITICALE, 21. 2006. Informações técnicas para a safra 2007: trigo e triticale. Passo Fundo: Embrapa Trigo, 2007. 114 p. (Embrapa Trigo. Documentos, 71).

TERUEL, D.A.; SMIDERLE, O.J. 1999. Trigo, p.13-37. In Castro $P$ R C, Kluge $R$ A. Ecofisiologia de cultivos anuais: trigo, milho, soja, arroz e mandioca. São Paulo, Nobel,

126

p. 